\title{
PENGARUH PENAMBAHAN ABU SERBUK KAYU DAN SERBUK BATU BATA BERDASARKAN UJI KONSOLIDASI DAN WAKTU PENURUNAN TANAH LEMPUNG
}

\section{THE EFFECT OF ADDITION OF WOOD POWDER AND BRICK POWDER BASED ON CONSOLIDATION TEST AND SETTLEMENT TIME OF CLAY}

\author{
Ranggaski Yoan Vianus ${ }^{1}$, Mohammad Ikhwan Yani², Fatma Sarie ${ }^{3}$ \\ ${ }^{1}$ Mahasiswa, Program Studi Teknik Sipil, Fakultas Teknik, Universitas Palangka Raya \\ 2,3 Dosen, Program Studi Teknik Sipil, Fakultas Teknik, Universitas Palangka Raya \\ *Korespondensi: yvranggaski@gmail.com
}

\begin{abstract}
ABSTRAK
Limbah industri kayu dan batu bata di Kalimantan Tengah sebagian besar tidak digunakan. Tujuan penelitian bertujuan adalah menganalisis sifat fisik dan mekanik tanah lempung di daerah Tumbang Rungan Kota Palangka Raya Kalimatan Tengah dan pengaruh penambahan abu serbuk kayu dan serbuk batu bata berdasarkan uji konsolidasi dan waktu penurunan tanah lempung dengan metode konsolidasi satu dimensi Terzaghi dengan penambahan bahan campuran variasi $2,5 \%, 5 \%$ dan 7,5\%. Pengujian yang dilakukan yaitu untuk mendapatkan nilai penurunan konsolidasi (Sc) dan nilai koefisien konsolidasi (Cv). Hasil dari penelitian menggunakan bahan campuran abu serbuk kayu dan serbuk batu bata diperoleh perubahan nilai Sc dan $\mathrm{Cv}$ terhadap tanah asli. Pada tanah asli memiliki nilai Sc (e) = 0,291 cm dan Cv (t50) =0,01913205 $\mathrm{cm}^{2} / \mathrm{det}, \mathrm{Cv}(\mathrm{t} 90)=0,031062161 \mathrm{~cm}^{2} / \mathrm{det}$ dan pada penambahan bahan campuran variasi $5 \%$ mengalami penurunan nilai $\mathrm{Sc}(\mathrm{e})=0,203 \mathrm{~cm}$ dan $\mathrm{Cv}(\mathrm{t} 50)$ $=0,00722173 \mathrm{~cm}^{2} / \mathrm{det}, \mathrm{Cv}(\mathrm{t} 90)=0,011679143 \mathrm{~cm}^{2} / \mathrm{det}$. Variasi campuran yang efektif untuk penambahan bahan campuran ke tanah lempung adalah variasi $5 \%$.
\end{abstract}

Kata Kunci: Abu Serbuk Kayu, Konsolidasi, Serbuk Batu Bata, Tanah Lempung, Waktu Penurunan

\begin{abstract}
The waste from the wood and brick industry in Central Kalimantan is largely unused. The research objective aims to analyze the physical and mechanical properties of clay soil in the Tumbang Rungan area of Palangka Raya City, Central Kalimantan and the effect of adding sawdust ash and brick powder based on the consolidation test and the time of subsidence of the clay soil using the Terzaghi one-dimensional consolidation method with the addition of a mixture of 2 variations $2,5 \%, 5 \%$ and $7,5 \%$. Tests conducted are to obtain the consolidation reduction value $(\mathrm{Sc})$ and the consolidation coefficient value $(\mathrm{Cv})$. The results of the study using a mixture of sawdust ash and brick powder obtained changes in the $\mathrm{Sc}$ and $\mathrm{Cv}$ values of the original soil. The original soil has a value of $\mathrm{Sc}(\mathrm{e})=0.291 \mathrm{~cm}$ and $\mathrm{Cv}(\mathrm{t} 50)=0.01913205 \mathrm{~cm}^{2} / \mathrm{s}, \mathrm{Cv}(\mathrm{t} 90)=0.031062161 \mathrm{~cm}^{2} / \mathrm{s}$ and the addition of a mixture of $5 \%$ variation of material has decreased the value of Sc $(e)=0.203 \mathrm{~cm}$ and $\mathrm{Cv}(\mathrm{t} 50)=$ $0.00722173 \mathrm{~cm}^{2} / \mathrm{s}, \mathrm{Cv}(\mathrm{t} 90)=0.011679143 \mathrm{~cm}^{2} / \mathrm{s}$. The effective mixture variation for adding mixed material to clay is a variation of $5 \%$.
\end{abstract}

\section{Keywords: Sawdust Ash, Consolidation, Brick Powder, Clay Soil, Settlement Time}




\section{PENDAHULUAN}

\section{Latar Belakang}

Tanah adalah suatu material yang terdiri dari partikel tanah padat, air dan udara. Konsolidasi adalah proses pengecilan volume pada tanah jenuh sempurna dengan permeabilitas rendah akibat pengaliran sebagian air pori. Pemberian beban pada tanah akan mengakibatkan meningkatnya tegangan yang bekerja pada tanah tersebut. Hal ini akan mengakibatkan berkurangnya volume tanah sehingga menyebabkan terjadinya penurunan konsolidasi. Teori konsolidasi satu dimensi Terzaghi digunakan untuk memprediksi penurunan serta waktu konsolidasi.

Di Kalimantan Tengah terdapat banyak tempat pembuatan batu bata dan industri kayu. Penambahan bahan campuran abu serbuk kayu dan serbuk batu bata bertujuan untuk memanfaatkan kembali hasil limbah dari industri tersebut. Pada pengujian konsolidasi ini bertujuan untuk mengetahui pengaruh penambahan bahan campuran abu serbuk kayu dan serbuk batu bata dengan metode konsolidasi satu dimensi Terzaghi.

\section{Rumusan Masalah}

1. Bagaimana sifat fisik dan mekanik tanah lempung yang berada di daerah Kelurahan Tumbang Rungan, Kota Palangka Raya, Kalimantan Tengah?

2. Bagaimana pengaruh penambahan penggunaan abu serbuk kayu dan serbuk batu bata berdasarkan uji konsolidasi dan waktu penurunan tanah lempung?

\section{Tujuan Penelitian}

1. Menganalisis sifat fisik dan mekanik tanah lempung di daerah Kelurahan Tumbang Rungan, Kota Palangka Raya, Kalimantan Tengah.

2. Menganalisis pengaruh penambahan abu serbuk kayu dan serbuk batu bata berdasarkan uji konsolidasi dan waktu penurunan tanah lempung.

\section{TINJAUAN PUSTAKA}

\section{Tanah Lempung}

Tanah Lempung mempunyai sifat permeabilitas sangat rendah dan bersifat plastis pada kadar air sedang. Tanah lempung memiliki ukuran partikel yang lebih kecil atau sama dengan 0,002 mm. Tanah lempung dengan ukuran mikronis sampai dengan submikrokonis ini terbentuk dari pelapukan unsur-unsur kimiawi (Bowles, 1991).

\section{Abu Serbuk Kayu}

Serbuk kayu didapatkan dari limbah gergaji yang berada di jalan Temanggung Tilung XXI kota Palangka Raya. Abu Serbuk kayu didapatkan dari hasil pembakaran limbah serbuk kayu. Setelah melalui proses pembakaran abu tersebut disaring pada saringan no.200 agar memperoleh ukuran butir halus.

\section{Serbuk Batu Bata}

Batu bata terbuat dari tanah liat dan dicampur dengan air, diaduk hingga merata lalu dicetak dan setelah kering dibakar ke tungku pembakaran batu bata. Serbuk batu bata didapatkan dari limbah batu bata yang berada di kota Palangka Raya. Batu bata ditumbuk agar menjadi halus dan setelah ditumbuk serbuk batu bata disaring menggunakan no.40 agar memperoleh ukuran halus.

\section{Konsolidasi}

Konsolidasi adalah suatu proses pengecilan volume secara perlahan-lahan pada tanah jenuh sempurna dengan permeabilitas rendah akibat pengaliran sebagian air pori (Craig, 1989).

Akibat adanya beban yang bekerja ditinjau dari lapisan tanah lempung jenuh dengan tebal awal $\mathrm{H}$, lapisan tanah menerima tambahan tegangan vertikal sebesar $\Delta \mathrm{p}$ dan terdapat hubungan perubahan volume angka pori (e), maka penurunan konsolidasi primer total Sc. Persamaan untuk penurunan konsolidasi primer total Sc yaitu:

$$
S c=\frac{e_{0}-e_{1}}{1+e_{0}} H
$$

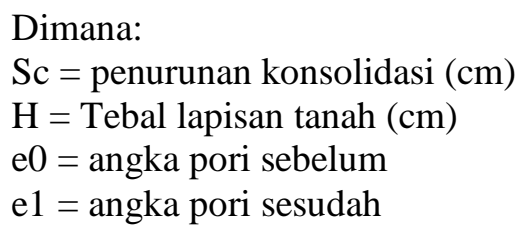

Koefisien konsolidasi (Cv) menentukan kecepatan waktu terjadinya konsolidasi. Untuk mendapatkan nilai $\mathrm{Cv}$ digunakan metode logaritma waktu dan metode akar waktu. Persamaan untuk metode logaritma waktu dan metode akar waktu 
yaitu:

$$
\begin{gathered}
C v=\frac{0,197 H d_{\mathrm{r}}^{2}}{t_{50}} \\
C v=\frac{0,848 H d_{\mathrm{r}}^{2}}{t_{90}}
\end{gathered}
$$

Dimana:

$\mathrm{Cv}=$ koefisien konsolidasi $\left(\mathrm{cm}^{2} / \mathrm{dtk}\right)$

$\mathrm{Hdr}=$ panjang aliran rata-rata yang harus ditempuh oleh air pori selama konsolidasi

\section{METODE PENELITIAN}

\section{Pemeriksaan Sifat Fisik Tanah Asli}

1. Pemeriksaan Kadar Air.

2. Pemeriksaan Berat Isi.

3. Pemeriksaan Berat Jenis.

4. Pemeriksaan Batas-Batas (Atterberg)

5. Pemeriksaan Analisa Saringan

\section{Pemeriksaan Sifat Mekanik Tanah Campuran}

\section{Pengujian Konsolidasi}

\section{Perencanaan Campuran}

Metode untuk pencampuran berdasarkan metode coba-coba (trial and error) yaitu tanah lempung dicampur dengan abu serbuk kayu dan serbuk batu bata dengan persentase penambahan $2,5 \%, 5 \%$ dan $7,5 \%$ dari berat tanah tersebut. Pengujian dilakukan dengan uji konsolidasi satu dimensi. Sampel uji konsolidasi menggunakan sampel tanah tak terganggu (undisturbed).

Tanah lempung yang digunakan adalah tanah yang diambil dari Kelurahan Tumbang Rungan, Kota Palangka Raya, Kalimantan Tengah. Serbuk kayu dan serbuk batu bata diambil dari Kota Palangka Raya.

\section{Proses Pencampuran Sampel Tanah}

Tanah lempung di keluarkan dari tabung kemudian di cetak ke dalam ring konsolidasi dan setelah itu ditimbang. Setelah itu, abu serbuk kayu dan serbuk batu bata ditimbang sesuai dengan berat yang di dapat setelah dikali dengan variasi campuran terhadap berat tanah lempung. Kemudian tanah lempung dicampur dengan abu serbuk kayu dan serbuk batu bata dengan melapisi bagian luar tanah sampai menutupi pori-pori dari tanah lempung tersebut lalu diuji.

\section{ANALISIS DAN PEMBAHASAN}

\section{Uji Sifat Fisik Tanah Lempung Asli}

Pengujian sifat fisik tanah yaitu parameter awal untuk merencanakan dan melaksanakan pembangunan konstruksi, pengujian sifat fisik tanah ini dilakukan di Laboratorium Mekanika Tanah Fakultas Teknik Universitas Palangka Raya.

Dari hasil pengujian sifat fisik tanah lempung didapatkan nilai-nilai berikut:

Tabel 1. Hasil Pengujian Sifat Fisik Tanah Lempung Asli

\begin{tabular}{llc}
\hline No & \multicolumn{1}{c}{ Jenis Pemeriksaan } & Nilai \\
\hline 1 & Kadar Air & 45,22 \\
2 & Berat Isi & 1,31 \\
3 & Berat Jenis & 2,7 \\
4 & Batas-Batas (Atterberg) & \\
& LL \% & 48,17 \\
& PL \% & 31,68 \\
& PI \% & 16,5 \\
& SL \% & 30,95 \\
5 & Analisa Saringan & \\
& Persentase Berat Tertahan & 49,61 \\
& $(\%)$ & 50,39 \\
\hline & Persentase Lolos No.200 (\%)
\end{tabular}

\section{Uji Konsolidasi Sifat Mekanik Tanah Lempung Campuran Serbuk Batu Bata + Abu Serbuk Kayu}

Sebelum melakukan pengujian konsolidasi dengan bahan campuran abu serbuk kayu dan serbuk batu bata. Terlebih dahulu melakukan pengujian konsolidasi dengan bahan campuran serbuk batu bata dengan variasi $2,5 \%, 5 \%$ dan $7,5 \%$ untuk mencari nilai optimal dari variasi tersebut dan variasi nilai optimal tersebut dicampurkan ke bahan campuran abu serbuk kayu.

Berdasarkan hasil pengujian konsolidasi diperoleh untuk nilai optimal serbuk batu bata yang akan di campurkan ke abu serbuk kayu adalah variasi campuran dengan persentase $2,5 \%$.

Setelah mendapatkan nilai optimal persentase campuran serbuk batu bata, selanjutnya akan dilakukan pengujian konsolidasi campuran serbuk batu bata $2,5 \%$ dengan abu serbuk kayu 


\section{$2,5 \%, 5 \%$ dan $7,5 \%$.}

Dari hasil pengujian konsolidasi sifat mekanik tanah lempung campuran abu serbuk kayu dan serbuk batu bata didapatkan nilai-nilai berikut:

Tabel 2. Hasil Pengujian Konsolidasi Campuran Abu Serbuk Kayu dan Serbuk Batu Bata

\begin{tabular}{cccc}
\hline$\%$ & $\begin{array}{c}\text { Cv (t50) } \\
\left(\mathbf{c m}^{2} / \mathbf{d e t}\right)\end{array}$ & $\begin{array}{c}\text { Cv (t90) } \\
\left(\mathbf{c m}^{2} / \mathbf{d e t}\right)\end{array}$ & Sc (e) \\
\hline 0 & 0,01913205 & 0,031062161 & 0,291 \\
2,5 & 0,01971991 & 0,047513962 & 0,272 \\
5 & 0,00722173 & 0,011679143 & 0,203 \\
7,5 & 0,01877732 & 0,057131160 & 0,246 \\
\hline
\end{tabular}

Sumber : Hasil Perhitungan (2020)

Berdasarkan hasil pengujian diatas pengaruh penambahan bahan campuran abu serbuk kayu dan serbuk batu bata mengalami penurunan konsolidasi (Sc) dari tanah asli dan waktu penurunannya $(\mathrm{Cv})$.

Dari Tabel 2 diatas nilai Sc (e) tanah asli dengan campuran abu serbuk kayu dan serbuk batu bata dapat dibuat grafik persentase dengan nilai Sc (e) seperti dibawah ini.

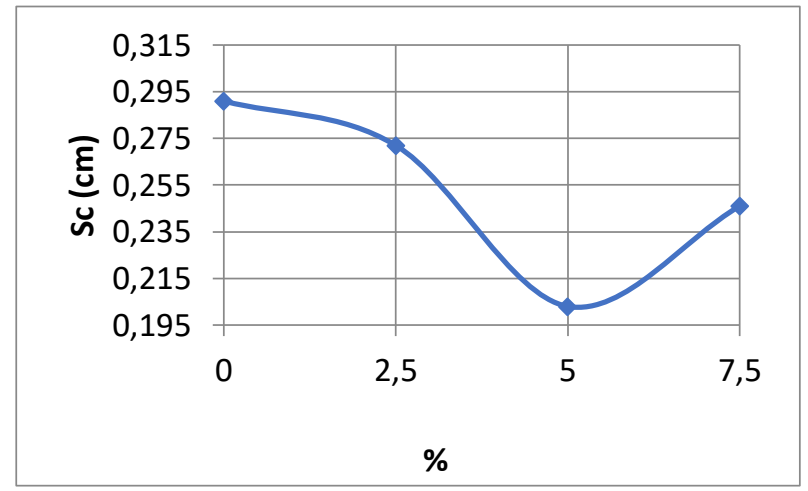

Gambar 1. Nilai Sc Abu Serbuk Kayu dan Serbuk Batu Bata

Pada Gambar 1 menunjukan hasil konsolidasi mengalami penurunan tanah lempung asli setelah penambahan abu serbuk kayu dan serbuk batu bata. Awalnya tanah asli memiliki nilai Sc (e) $=0,291 \mathrm{~cm}$ setelah dicampurkan bahan campuran terjadi penurunan terbesar di variasi persentase $5 \%$ dengan nilai Sc (e) $=0,203 \mathrm{~cm}$.

Dari Tabel 2 nilai koefisien konsolidasi $\mathrm{Cv}$ (t50) tanah asli dengan campuran abu serbuk kayu dan serbuk batu bata dapat dibuat grafik nilai $\mathrm{Cv}$ (t50) dengan tegangan seperti dibawah ini.

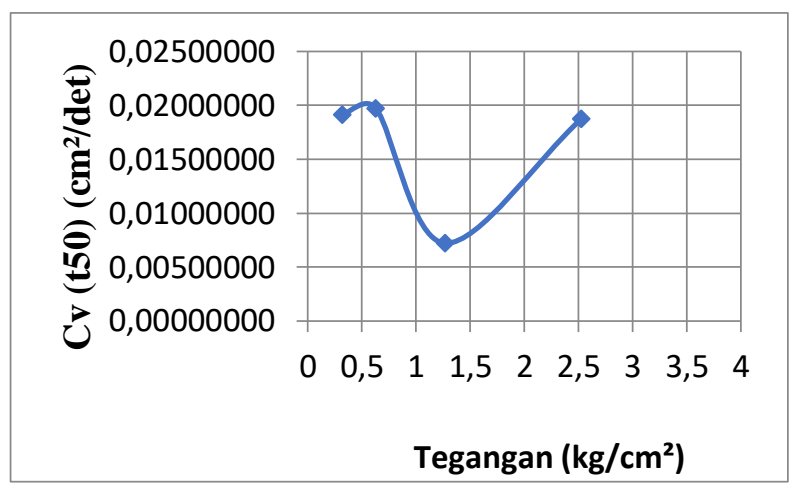

Gambar 2. Nilai Cv (t50) dengan Tegangan Abu Serbuk Kayu dan Serbuk Batu Bata

Pada Gambar 2 menunjukan nilai kofisien konsolidasi $\mathrm{Cv}$ (t50) mengalami penurunan tanah lempung asli setelah penambahan abu serbuk kayu dan serbuk batu bata. Awalnya tanah asli memiliki nilai $\mathrm{Cv}(\mathrm{t} 50)=0,0191 \mathrm{~cm}^{2} /$ det setelah dicampurkan bahan campuran terjadi penurunan di variasi persentase $5 \%$ dengan nilai $\mathrm{Cv}(\mathrm{t} 50)=0,0072$ $\mathrm{cm}^{2} /$ det.

Dari Tabel 2 nilai koefisien konsolidasi $\mathrm{Cv}$ (t90) tanah asli dengan campuran abu serbuk kayu dan serbuk batu bata dapat dibuat grafik nilai $\mathrm{Cv}$ (t90) dengan tegangan seperti dibawah ini.

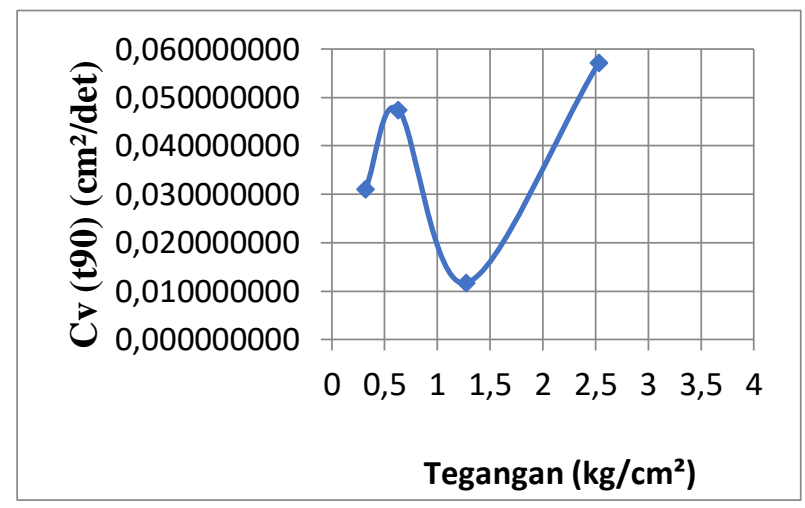

Gambar 3. Nilai Cv (t90) dengan Tegangan Abu Serbuk Kayu dan Serbuk Batu Bata

Pada Gambar 3 menunjukan nilai kofisien konsolidasi $\mathrm{Cv}$ (t50) mengalami penurunan tanah lempung asli setelah penambahan abu serbuk kayu dan serbuk batu bata. Awalnya tanah asli memiliki nilai $\mathrm{Cv}(\mathrm{t} 90)=0,0311 \mathrm{~cm}^{2} /$ det setelah dicampurkan bahan campuran terjadi penurunan di variasi persentase $5 \%$ dengan nilai $\mathrm{Cv}(\mathrm{t} 90)=0,0117$ $\mathrm{cm}^{2} /$ det. 


\section{PENUTUP}

\section{Kesimpulan}

Berdasarkan hasil penelitian dan pembahasan yang telah diuraikan dapat disimpulkan beberapa hal sebagai berikut:

1. Dari hasil pengujian sifat - sifat fisik tanah asli didapat nilai, kadar air $(w)=45,22 \%$; berat isi $\left(\gamma_{\mathrm{d}}\right)=1,31 \mathrm{~g} / \mathrm{cm}^{3}$; berat jenis $(G s)=2,70$; batas - batas Atterberg yaitu Batas Cair (Liquid Limit) $=48,17 \%$; Batas Plastis (Plastic Limit) $=31,68 \% ;$ Indeks Plastisitas (Plasticity Index) $=16,50 \%$; Batas Susut (Shrinkage Limit) $=$ 30,95\%; Analisis saringan persentase lolos saringan No. $200=50,39 \%$.

2. Dari hasil pengujian konsolidasi tanah asli tanpa bahan campuran didapat nilai Sc (e) = $0,291 \mathrm{~cm}$. Setelah penambahan campuran serbuk batu bata dan abu serbuk kayu didapat persentase 5\% mengalami penurunan nilai Sc (e) $=0,203 \mathrm{~cm}$ dengan selisih nilai Sc (e) = $0,088 \mathrm{~cm}$ dari tanah asli.

3. Dari hasil pengujian konsolidasi tanah asli tanpa bahan campuran didapat nilai $\mathrm{Cv}(\mathrm{t} 50)=$ $0,01913205 \mathrm{~cm}^{2} /$ det dan $\mathrm{Cv} \quad(\mathrm{t} 90)=$ $0,031062161 \mathrm{~cm}^{2} /$ det. Setelah penambahan campuran serbuk batu bata dan abu serbuk kayu didapat persentase 5\% mengalami penurunan nilai $\mathrm{Cv}$ (t50) $=0,00722173$ $\mathrm{cm}^{2} / \mathrm{det}, \mathrm{Cv}(\mathrm{t} 90)=0,011679143 \mathrm{~cm}^{2} / \mathrm{det}$ dengan selisih $\mathrm{Cv}(\mathrm{t} 50)=0,0119 \mathrm{~cm}^{2} / \mathrm{det}$ dan $\mathrm{Cv}(\mathrm{t} 90)=0,0194 \mathrm{~cm}^{2} / \mathrm{det}$ dari tanah asli.

\section{Saran}

Setelah melakukan penelitian ini, dapat disampaikan beberapa saran sebagai berikut:

1. Ketelitian dalam penimbangan dan pembacaan dial sangat diperlukan untuk memperlancar analisis peneltian

2. Jika pembuatan sampel proses pencampuran harus dengan benar saat mencampurkan bahan campurannya.

\section{DAFTAR PUSTAKA}

ASTM Standards. (1963). ASTM D 422-63, Standard Test Method for Particle-Size Analysis of Soils. v.63.

ASTM Standards. (1989). ASTM D 2435-50. Standard Test Method for One-Dimensional Consolidation Properties of Soils.

ASTM Standards. (1995). ASTM D 4318-95,
Standard Test Method for Liquid Limit, Plastic Limit, and Plasticity Index of Soils, v.04, p.114.

ASTM Standards. (1998). ASTM D 2216-98, Standard Test Method for Laboratory Determination of Water (Moisture) Content of Soil, Rock, and Soil Aggregate Mixtures.

ASTM Standards. (2002). ASTM D 854-02, Standard Test Method for Particle Specific Gravity of Soil Solids by Water Pycnometer.

Bowles, J E. (1991). Sifat-sifat Fisik Tanah dan Geoteknis Tanah. Erlangga. Jakarta.

Craig, R. F. (1989). Mekanika Tanah edisi keempat Erlangga. Jakarta.

Das, Braja M. (1995). Mekanika Tanah Jilid I (Prinsip-prinsip Rekayasa Geoteknis). Erlangga. Jakarta.

Hardiyatmo, H. C. (2002). Mekanika Tanah I, Edisi ke tiga. Penerbit PT, Gramedia Pustaka Utama, Jakarta.

Terzaghi, K., \& Peck, R. B. (1987). Mekanika Tanah dalam Praktek Rekayasa I, Alih bahasa Bagus, W., dan K. Benny. Erlangga, Jakarta.Teknik Universitas Sam Ratulangi. 